\title{
Breastfeeding Practices of Postnatal Mothers: Exclusivity, Frequency and Duration
}

\author{
Chiejina EN, Anieche JE, Odira CC
}

Department of Nursing Science, Faculty of Health Sciences and Technology, Nnamdi Azikiwe University Nnewi Campus

Nigeria.

\begin{abstract}
Mothers who perceive breastfeeding to be healthier, easier and more convenient breastfeed longer than those who perceive that breastfeeding is restrictive, inconvenient and uncomfortable. This study focused on the breastfeeding practices of postnatal mothers with regard to exclusivity, frequency and duration. It was a cross-sectional research design covering the three levels of health care institutions in the South-East Zone of Nigeria. Convenient sampling method was used to select 299 postnatal mothers who visited infant welfare clinics along with their infants. Three research questions and one null hypothesis guided the study. The instruments used for data collection were questionnaire on patterns of breastfeeding by postnatal mothers (QPBF) and checklist on health status of infants with varied breastfeeding patterns (CHSIVBP). Frequency distribution and percentages were used to answer the research questions while chi-square test was used in testing the null hypothesis at 0.05 level of significance. The result showed that most of the postnatal mothers practiced EBF for a short period, majority breastfed their infants on demand day and night, and majority also reported that their infants suckle the breast for more than 20minutes. Also breastfeeding patterns of the postnatal mothers was found to differ significantly across the three levels of health care institutions. Childbearing mothers need to be motivated on the need to practice EBF for six month postpartum.
\end{abstract}

Keywords-Breastfeeding, Duration, Exclusivity, Frequency, Postnatal Mothers.

\section{INTRODUCTION}

Breast milk is nature's most precious gift to the newborn, an equivalent of which is yet to be innovated by the scientific community despite tremendous advances in science and technology (Faridi, 2008). Scientific research studies have clearly proved that breastfeeding provides the most suitable nutrition for infants and protects them against infections, allergies and asthma (WHO, 2001). Other documented benefits of breastfeeding to the mother include emotional wellbeing, economic benefits, spacing of pregnancies, protection against breast cancer and reduced incidence of type 1 diabetes mellitus (Sadauskaite-kuehne et al, 2004; WHO, 2001).

In the context of Millennium Development Goal 4, scientific evidences have highlighted initiation of breastfeeding immediately after birth without squeezing out colostrum and exclusive breastfeeding for the first six months as the key to tackle infant nutrition and also survival of infants (WHO and UNICEF, 2003). Studies on accelerating child survival published in the Breastfeeding Promotion Network of India (BPN) Lancet clearly established that universalization of early initiation of breastfeeding within half an hour after birth has tremendous potential in reducing $31 \%$ of neonatal deaths which is about $10 \%$ of total child deaths (Gupta, 2007). WHO(2001) warned that early introduction of supplementary feeding usually has a negative effect on the return to exclusive breastfeeding. Piwoz et al (1994) observed that supplements may not be given daily but they are unlikely to be withdrawn once they are introduced. According to Wilmoth and Elder (1995), supplemental feeding exposes infants to foreign contaminants and infection at a very vulnerable stage of life. Brown, Dewey and Allen (1998) added that this may likely explain the higher infant mortality rate of partially bottle-fed infants compared with exclusively breastfed infants. Researchers have shown that exclusive breastfeeding is associated with increased weight gain among babies of normal birth weight (Scarlett et al, 1996). Despite this observed benefit, studies have also shown that early introduction of infant formula and other foods have remained a problem among postnatal mothers (Almroth and Latham, 1982). Hence this study intends to determine the breastfeeding patterns of postnatal mothers with regard to exclusivity, duration and the frequency of breastfeeding.

\section{Research Questions.}

- To what extent do postnatal mothers practice exclusive breastfeeding? 
- How frequent do postnatal mothers breastfeed their infants?

- How long do postnatal mothers allow their infants to suckle the breast during each feed?

\section{Hypothesis.}

- Breastfeeding patterns of postnatal mothers do not significantly differ across the levels of health care institutions.

\section{MATERIALS AND METHODS}

Design and sampling.

This study was a cross-sectional research design. A convenient sample of 299 postnatal mothers who visited infant welfare clinics along with their infants in three levels of health care institutions (two health centres, two General Hospitals and two teaching hospitals) were used for the study. Ethical approval was obtained for the study and informed consent was obtained from the mothers. Inclusion criteria for the study were all healthy postnatal mothers irrespective of parity who were breastfeeding their infants, and all infants born at term aged 0-12months who were breastfed irrespective of the pattern of breastfeeding. Exclusion criteria were preterm babies and babies with any other underlying disorder (organic and non -organic) and mothers with medical disorders that could interfere with breastfeeding. Also mothers who indicated not to participate were excluded from the study, and also their infants were not used. The mothers were approached by the researchers at the time of their visits to the infant welfare clinics along with their infants. Interview method was adopted by the researchers to obtain data from the respondents at that time as well. Confidentiality was ensured by not including names of the respondents in the data collection.

\section{Instrument.}

Two instruments (Questionnaire and Checklist) were used among the mother-infant pair for data collection.
Questionnaire on patterns of breastfeeding by postnatal mothers (QPBF) was used to obtain data on characteristics of the postnatal mothers. Section A of the instrument elicited information on the demographic characteristics of the respondents (e.g age, marital status, educational level, parity and employment status, etc). Section B of the questionnaire elicited information on the breastfeeding patterns adopted by the postnatal mothers (eg. time of commencement of breastfeeding, duration of exclusive breastfeeding, time of commencement of partial breastfeeding, frequency of breastfeeding, additional feeds with breastfeeding, etc). The responses to section $\mathrm{B}$ of QPBF were scored on a 4-point scale ranging from 1 point for poor pattern of breastfeeding, 2 points for fair pattern of breastfeeding, 3 points for good pattern of breastfeeding and 4 points for normal/ideal breastfeeding pattern. Checklist on the health status of infants with varied breastfeeding patterns (CHSIVBP) was developed for the study by the researchers to obtain information on the responses of the infants to the breastfeeding patterns adopted by their mothers. These data were obtained confidentially from the medical records of the infants, and included such information as the infants birth weight, age, weight gain pattern, height, nutritional status, vulnerability to infection, etc. The instruments (QPBF) and CHSIVBP) were tested for reliability, and a test-retest reliability coefficient of 0.72 and 0.75 respectively were obtained over a one month interval.

\section{Data Analysis.}

Standard descriptive statistics of means and standard deviation were used to summarize the variables. Frequencies and percentages were used to answer the research questions while Chi-square test was adopted in testing the null hypothesis at 0.05 level of significance. SPSS version 21 was used for the data analysis. 


\begin{tabular}{|c|c|c|c|}
\hline & $\mathbf{N}$ & Mean & Std. Deviation \\
\hline Age of Mother & 297 & 27.5926 & 5.81171 \\
\hline Level of health institution & 299 & 1.9967 & .81717 \\
\hline Level of Health institution 2 & 299 & 1.9967 & .81717 \\
\hline MS & 299 & 1.0301 & .17115 \\
\hline Edu & 299 & 3.3344 & 60909 \\
\hline Parity & 299 & 1.5886 & .49291 \\
\hline Employment Status & 299 & 1.3746 & .48483 \\
\hline Family Type & 299 & 1.0100 & .09983 \\
\hline Religion & 299 & 1.0100 & .09983 \\
\hline Place of Residence & 299 & 1.3378 & .47375 \\
\hline Time of Commencing Breastfeeding & 281 & 3.7331 & .70958 \\
\hline EBF Duration & 197 & 2.6447 & 1.17179 \\
\hline Commencement of Partial BF & 241 & 2.0415 & 1.26423 \\
\hline Breastfeeding Frequency & 296 & 3.6892 & .71641 \\
\hline Breast Sucking Duration & 299 & 3.0602 & .94641 \\
\hline Additional Food & 230 & 2.7522 & 1.44003 \\
\hline Breastfeeding Pattern & 299 & 2.6210 & .70112 \\
\hline Sex of Infant & 299 & 1.5619 & .49699 \\
\hline Birth Weight & 296 & 3.3274 & .49365 \\
\hline Present Weight & 89 & 5.3719 & 2.14391 \\
\hline Weight Gain Pattern & 288 & 1.0556 & .22946 \\
\hline Height Pattern & 298 & 1.0470 & .22728 \\
\hline Nutritional Status & 299 & 1.0635 & .24435 \\
\hline General Body System & 299 & 1.1271 & .36255 \\
\hline Vulnerability of the Infant to infection & 299 & 1.1204 & .32598 \\
\hline Thriving of Infant & 299 & 1.0870 & .28224 \\
\hline Health Status & 299 & 1.0797 & .24013 \\
\hline
\end{tabular}

Table 1 shows the descriptive statistics of the measured variables. The mean age of the postnatal mothers was 27.5926 with standard deviation (SD) of 5.81171, mean for the levels of health care institutions 1.9967 with SD of 0.81717; for marital status (MS) of the mothers, the mean was 1.0301 with SD of 0.17115 , mean for educational level of the mothers 3.3344 with SD 0.60909 , mean for parity of the mothers was 1.5886 with SD of 0.49291 ; mean for employment status of the mothers was 1.3746 with SD of 0.48483 . Family type of the mothers had mean score of 1.0100 with SD of 0.09983 ; religion had mean score of
1.0100 with SD 0.09983 , place of residence of the mothers had mean of 1.3378 with SD 0.47375 . For time of commencement of breastfeeding the mean was 3.7331 with SD 0.70958; mean for exclusive breastfeeding (EBF) duration 2.6447 with SD 1.17179; mean for time of commencement of partial BF was 2.0415 with SD of 1.26423; breastfeeding frequency had mean of 3.6892 with SD of 0.71641 ; breast suckling duration had mean of 3.0602 with SD 0.94641; mean for additional food was 2.7522 with SD 1.44003; for breastfeeding patterns the mean was 2.6210 with SD 0.70112, mean for sex of the 
infants was 1.5619 with SD of 0.49699 ; birth weight of the infants had mean of 3.3274 with SD of 0.49365 ; mean of the present weights of the infants at time of data collection was 5.3719 with SD of 2.14391. weight-gain pattern of the infants had mean of 1.0556 with SD of 0.22946; mean height for the infants was 1.0470 with SD 0.22728; mean for the infants nutritional status 1.0635 with SD 0.24435 ; for infants' general body system the mean was 1.1271 with SD of 0.36255 . For vulnerability of the infants to infection, the mean was 1.1204 with SD 0.32598; mean for thriving of the infants was 1.0870 with SD of 0.28224 while the health status of the infants had mean of 1.0797 with SD of 0.24013 .

Table.2: Extent of practice of Exclusive breastfeeding (EBF) by postnatal mothers

\begin{tabular}{|l|l|c|l|l|}
\hline Variable & EBF Duration & N & percent & Valid \% \\
& .00 & 2 & 0.7 & 1.0 \\
& One month & 44 & 14.7 & 22.3 \\
& Two months & 38 & 12.7 & 19.3 \\
Exclusive & Three months & 51 & 17.1 & 25.9 \\
Breastfeeding & $4-6$ months & 62 & 20.7 & 31.5 \\
(EBF) & Total & 197 & 65.9 & 100.00 \\
& Missing system & 102 & 34.1 & \\
& Total & 299 & 100.00 & \\
\hline
\end{tabular}

Table 2 shows that out of 197 postnatal mothers, 44(22.3 valid \%) exclusively breastfed their infants for one month, 38(19.3 valid \%) exclusively breastfed their infants for two months, 51(25.9 valid \%) exclusively breastfed for three months while $62(31.5$ valid \%) breastfed their infants exclusively for 4 to 6 months.

Table.3: Frequency of breastfeeding by postnatal mothers

\begin{tabular}{|l|l|l|l|l|}
\hline Variable & Breastfeeding frequency & $\mathbf{N}$ & $\mathbf{\%}$ & Valid \% \\
\hline \multirow{5}{*}{ Breastfeeding } & Every 4 hours & 9 & 3.0 & 3.0 \\
& Every 2 hours & 17 & 5.7 & 5.7 \\
& On demand at day time only & 31 & 10.4 & 10.5 \\
& On demand day and night & 239 & 79.9 & 80.7 \\
& Total & 296 & 99.0 & 100.0 \\
& Missing system & 3 & 1.0 & \\
& Total & 299 & 100.0 & \\
\hline
\end{tabular}

Above table 3 shows that out of 296 postnatal mothers, 9(3.0 valid \%) breastfed their infants every 4 hours, 17(5.7 valid \%) breastfed their infants every 2 hours, 31(10.5 valid \%) breastfed their infants on demand at day time only, while 239(80.7 valid $\%$ ) breastfed their infants on demand at both day and night.

Table.4: Duration of suckling by the infants of postnatal mothers

\begin{tabular}{|l|l|l|}
\hline Duration of suckling & Frequency & Valid \% \\
\hline$<10$ minutes & 22 & 7.4 \\
$11-15$ minutes & 59 & 19.7 \\
$16-20$ minutes & 97 & 32.4 \\
$>20$ minutes & 121 & 40.5 \\
$\quad$ Total & 299 & 100.0 \\
& & \\
\hline
\end{tabular}

Table 4 shows that out of 299 post natal mothers $22(7.4 \%)$ indicated that their infants suckle the breast for less than 10 minutes during each feeding, the infants of 59 (19.7\%) postnatal mothers suckle the breast for 11 to 15 minutes; the duration of 
suckling for the infants of 97 (32.4\%) mothers was 16- 20 minutes while the suckling period for the infants of 121 (40.5\%) mothers was more than 20 minutes.

Table.5: Chi- Square test comparison of the breast feeding patterns of post natal mothers across the primary, secondary, and tertiary health institutions

\begin{tabular}{|l|l|l|l|l|l|l|l|}
\hline Variable & $\begin{array}{l}\text { Levels of Health } \\
\text { Institutions }\end{array}$ & $\mathbf{N}$ & Mean Rank & df & $\mathbf{X}^{2}$-cal & p-value & $\begin{array}{l}\text { Level } \\
\text { significance }\end{array}$ \\
\hline Breastfeeding & Primary & 100 & 153.05 & 2 & 2.681 & 0.262 & 0.05 \\
pattern & Secondary & 100 & 138.87 & & & & \\
& Tertiary & 99 & 158.16 & & & & \\
\cline { 2 - 6 } & Total & 299 & & & & & \\
\hline
\end{tabular}

In Table 5, the $\mathrm{X}^{2}$ of 2.681 was more than the p-value of 0.262 at 0.05 level of significance. Therefore the null hypothesis is rejected. The breastfeeding patterns of post natal mothers differ significantly across the primary, secondary, and tertiary health care institutions

\section{DISCUSSION}

Finding from the study indicate that post natal mothers practice exclusive breast feeding (EBF) but most of them $(133=67.5$ valid $\%)$ did not extend the practice up to four to six months age of the infants as stipulated by WHO \& UNICEF (2003) (table2). Some (22.3\%) practiced EBF for only one month, some (19.3\%) for two months, while $25.9 \%$ practiced EBF for three months. Studies have shown that mothers find it difficult to adhere to the expert recommendation for continued and exclusive breastfeeding (Whalen and Cramton, 2010). WHO (2003) reported that only $35 \%$ of infants worldwide were exclusively breastfed during the first six months of life. These reports as well as the findings of this study imply that EBF is ignored by most mothers.

Finding from the study indicate that few postnatal mothers had scheduled time of breastfeeding their infants. $3 \%$ fed their infants at 4 hourly intervals while $5.7 \%$ fed their infants on 2 hourly schedule, $10.5 \%$ fed their infants on demand at day time only, but majority (80.7\%) breastfed their infants on demand day and night (table 3). This result is similar to the findings in some previous studies. Kurzewski and Gradner (2005) reported that majority of mothers feed their babies when they are hungry and/or crying (that is, demand feeding), few babies are fed on schedule, some babies are breastfed on 3 to 6 occasions per day, some mothers breastfeed more than 11 times per day; and that overnight, $68 \%$ of babies are fed less than four times, $25 \%$ breastfed five to six times and a few (5\%) feed more than seven times. However, Subbiah and Jeganathan (2012) reported that some mothers said they avoid breastfeeding baby at night because it causes colic to the baby. It is important to note that whatever frequency of breastfeeding one adopts, experts (WHO, 2003; Pilliteri, 1999) have advised that infants should be breastfed on demand.

The result of the study showed that for majority of the postnatal mothers $(40: 5 \%)$, their infants suckled the breast for more than 20 minutes while in few mothers (7.4\%), the duration of suckling for their infants was $<10$ minutes (table 4). Pilliteri (1999) stated that often, newborns that are being breastfed drop off to sleep during the first few feedings, and that mothers should stimulate and awake such babies by stroking the baby's back, tickling the bottom of the baby's foot or by changing the baby's position during feeding. kurzewski and Gardner (2005) in their study found out that the duration of suckling was mostly 16-20 minutes, less than 10 minutes for some, 11 to 15 minutes, and more than 20 minutes for some infants. Suckling promote milk production and milk flow. According to Pilliteri (1999) the primary method for relieving engorgement is emptying the breasts of milk by having the infants suck more than previously, or at least continuing to suck as much as before. Research suggests that nipple soreness is not related to the length of time the infants is at the breast but to improper positioning or improper removal of the infant from the breast (Littleton and Engebretson, 2007)

Finally, findings from the study indicate that the breastfeeding patterns of the postnatal mothers differ significantly $\left(\mathrm{X}^{2}=2.681 ; \mathrm{p}\right.$-value $\left.=0.262\right)$ across the primary, secondary and tertiary health care institutions (table 5). Previous studies similarly have shown that hospital practices such as early breastfeeding initiation, infant rooming-in and providing breastfeeding only have helped to improve breastfeeding initiation, duration and exclusivity (Dennis, 2002; Murray, Rickketts \& Dellaport, 2007; Dieteritch et al, 2013). Nkala \& Msuya (2011) have 
also noted that health system practices influence breastfeeding in different areas in developing countries. Also it is noteworthy that primary, secondary and tertiary health care institutions differ in their scope of responsibilities. The primary level focuses on preventive care while the secondary and tertiary levels focus on diagnoses and referrals. These differences in the scope of functions could contribute to the significant difference in the breastfeeding patterns of the postnatal mothers across the three levels of health care institutions.

\section{CONCLUSIONS}

The study indicate shortfall in the duration of EBF, high rate of demand feeding at both day and night as well as significant difference in the breastfeeding patterns of postnatal mothers across the primary, secondary and tertiary health institutions.

\section{REFERENCES}

[1] Almroth S, Latham MC.(1982). Breastfeeding Practices in rural Jamaica. Journal of Tropical Pediatrics, 28, 103-109.

[2] Brown KH, Dewey KG, Allen LH. (1998). Complementary feeding of young children in developing countries: a review of current scientific knowledge. Geneva: WHO.

[3] Dennis CL. (2002). Breastfeeding initiation and duration: a 1990-2000 literature review. Journal of obstetric Gyneological Nursing, 31(1), 12-32.

[4] Dieterich CM, Felice JP, O'Sullivan E, Rasmussen KM. (2013). Breastfeeding and Health Outcomes for the Mother-Infant Dyad. Pediatr clin North Am, 60 (1), 31-48.

[5] Faridi MMM. (2008). Health care System in the Protection, Promotion and support of Breastfeeding. Solution Exchange for $\mathrm{MCH}$ community Newsletter, Breastfeeding month special, August 2008, 7-8.

[6] Gupta A. (2007). Faulty feeding practices and malnutrition. Breastfeeding Promotion Network of India. Available from URL: http://www.bpni.org/cgi/wbw2006asp.Viewed on 2 December 2006.

[7] Kurzewski K, Gardner JM. (2005). Breastfeeding patterns among six-week-old term infants at University Hospital of the West Indies.West Indian Medical Journal, vol. 54 (1) 28-33.

[8] Littleton LY, Engebretson JC. (2007). Maternity Nursing Care. Haryana: Thomson Delmar Learning.
[9] Murray EK, Ricketts S, Dellaport J. (2007). Hospital Practices that increase breastfeeding duration: results from a population-based study. Birth, 34 (3), 202-211.

[10]Nkala JE, Msuya SE. (2011). Prevalence and predictors of exclusive breastfeeding among women in Kigoma region, western Tanzania: a community-based cross-sectional study. International Breastfeeding Journal, vol. 6, article 17.

[11] Pilliteri A. (1999). Maternal \& child Health Nursing ( $3^{\text {rd }}$ ed.). New York: Lippincott.

[12] Piwoz EG, Black RE, Lopez de Romana G, Creed de Kanasiario M, Brown KH. (1994). The relationship between infants proceeding appetite, illness and growth performance and mothers' subsequent feeding practice decisions. Social Science Medicine, 1994, 39, 851-860.

[13] Sadauskaite - Kuehne V, Ludvigsson J, Padaiga Z, Jasinskiene E, Samuelsson U. (2004). Longer breastfeeding is an independent protective factor against development of Type I diabetes mellitus in childhood. Diabetes Metab Res Rev, 20, 150-157

[14] Scarlett D, Cargill M, Lyn-Sue J, Richardson S, Mc.Caw-Binns A. (1996). Breastfeeding prevalence among six-week old infants at the University Hospital of West Indies. West Indian Medical Journal, 45, 14-17.

[15] Subbiah N, Jeganathan A. (2012). Sociocultural Beliefs influencing Breastfeeding Practices Among Primi Postnatal mothers residing in Urban Slum Area of Delhi. Health and Population-Perspectives and Issues, 35 (2), 61-73.

[16] Whalen B, Cramton R. (2010). Overcoming barriers to breastfeeding continuation and exclusivity. Current Opinion in Pediatrics, vol. 22, 5, 655-663.

[17] WHO. (2001). Global strategy for infant and young child feeding; the optimal duration of exclusive breastfeeding. Fifty -fourth World Health Assembly, Provisional Agenda item 13.1. A54/INF. DOC./4. 1 May 2001.

[18] WHO/UNICEF. Geneva: WHO; 2003. Global strategy for infant and young child feeding, pg 5-10.

[19] Wilmoth TA, Elder JP.(1995). An assessment of research on breastfeeding promotion strategies in developing countries. Social Science Medicine, 41, 579-594. 